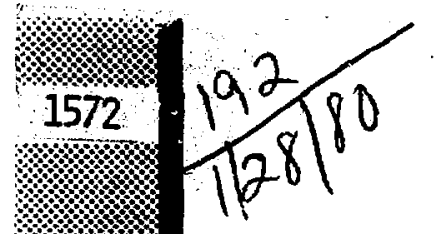

\title{
CURRENT PENETRATION IN THE PLT TOKAMAK
}

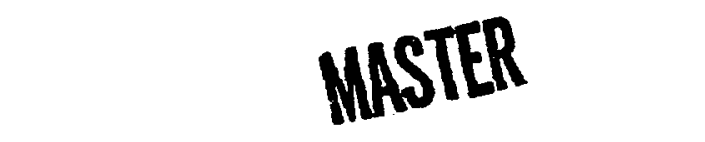

\section{PLASMA PHYSICS LABORATORY}

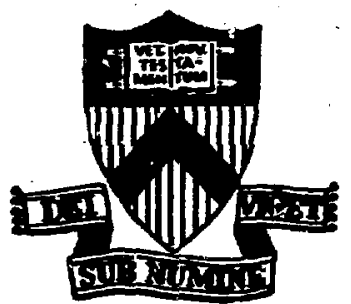

IUSTRIBUTIOH OF THIS DORJEETT IS UMLIMITED

\section{PRINCETON UNIVERSITY PRINCETON, NEW JERSEY}

Th1s work was expported by the U. S. Department of Energy Contract No. EY-76-C-02-3073. Reproduct1on, tranalation, publication, use and disposel, in whole or in part, by or for the United States Govermant is parntted. 


\section{Current Penetration in the PLT Tokamak}

by

R. J. Hawryluk, N. Bretz, D. Dimock, E. Hinnov D. Johnson, D. Monticello, D. McCune and S. Suckewer

Plasma Physics Laboracory Princeton University princeton, New JeI iey USA 08544

\section{ABSTRACT}

Current penetration in the PLT jokamak is modeled by a one dimensional magnetic field difiusion code assuming neoclassical resistivity. The code lises the measured temperature and density profiles as well as current and voltage measurements to evaluate $z_{\text {eff }}$. Under certain conditions, the resulting calculations of $z$ eff during the startup phase have been considerably larger than the $z_{\text {eff }}$ determined spectroscopically indicating the presence of an enhanced current penetration mechanism. Furthermore, these valculations indicate that the gross energy confinement time is substantially less during the startup phase than in the quasi-steady state.

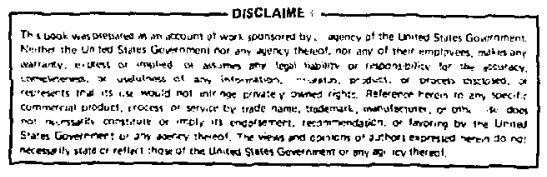




\section{INTRODUCTION}

Prior to the operation of the PLT tokamak, Düchs et al. [1] calculated the skin effect during the startup phase of the PIT discharge. Assuming pseudoclassical electron heat transport, they predicted the existence of a large skin effect, unless a substantial enhancement of either the resistivity or of the heat conduction was present. Experimentally on ST, evidence had been found that the current penetration time was less than predicted by neoclassical theory [2]. It is therefore of great interest to examine current penetration on PLT. In the most recent series of experiments on PLT as a result of low power discharge cleaning and titanium gettering, it has been possible to substantially decrease the impurity content $[3,4]$. This yields a relatively high conductivity which makes possible the evaluation of current penetration during the startup phase and a comparison with the models used in Ref. 1. The objective of this paper is to examine the assumptions commonly used in one dimensional transport codes ragarding magnetic field diffusion and power loss during the startup phase (for instance, see Ref. $1,5,6)$.

In Sec. II, the approach used to analyze the PLT experiments will be discussed. In Sec. III, the experimental measurements are compared with a one dimersional magnetic field calculation, and in Sec. IV the results are discussed. 


\section{ANALYSIS}

In calculating the skin effect auring the startup phase, two different approaches have been used. The approach used by Düchs et al. $[1,6]$, among others, attempts to predict the electron temperature profile by solving the electron energy balance equation. If impurities are taken explicitly into account, the $z_{\text {eff }}$ profile is also calculated [6] $\cdot\left(z_{\text {eff }}=\sum n_{i} z_{i}{ }^{2} / \Sigma n_{i} z_{i}\right.$ where $n_{i}$ is the density of ions of charge $z_{i}$ ) The temperature and $z_{\text {eff }}$ profiles are required to compute the plasma resistivity which in turn is used to solve the magnetic field diffusion equation. In order to compare the skin effect caleulations with the experiment, the electron temperature profiles must be accurately predicted. The difficulty with this approach is that the temperature profile is sensitive to tne assumptions regarding impurity flux, transport and radiation as well as the parametric dependence of plasma transport coefficients. In practice, the transport and impurity models must be adjusted to obtain an adequate fit to the measured electron temperature profile before the implications of the magnetic field diffusion model can be addressca. An alternative approach, which has been used in this paper and by Ross and cardwell [7] on ST data, is to use the measured temperature and density profiles in evaluating the neoclassical conductivity, $\sigma(r, t)$ [8]. The conductivity is used in solving the one dimensional poloidal magnetic field diffusion equation, 


$$
\frac{\partial B_{\theta}}{\partial t}=\frac{\partial}{\partial r} \frac{1}{r \mu_{0} \sigma(r, t)} \frac{\partial r B_{\theta}}{\partial r} \text {, }
$$

in cylindrical coordinates subject to the usual boundary conditions

$$
B_{\theta}(0)=0
$$

and

$$
B_{\theta}(a)=\frac{\mu_{0}{ }_{p}}{2 \pi a}
$$

where $I_{p}$ is the measured plasma current and a is the minor radius. $z_{\text {eff }}$ is assumed to be independent of minor radius and the magnitude of $\mathrm{z}_{\text {eff }}$ is adjusted by iteration to obtain agreement with the measured surface voltage. The computed $z_{\text {eff }}$ is then compared with the spectroscopically determined value of $Z_{\text {eff }}$ to evaluate the enhancement required in the neoclassical resistivity.

In our analysis the electron temperature and density profiles, used in the calculation of $\sigma(r, t)$, were obtained with the multichannel Thomson scattering system [9]. In some cases data from several discharges were averaged. Spline fits were used for interpolation and smoothing of the profiles both radially and temporally. The temperature profiles before the first measured profile were obtained by linear interpolation. The calculations of $z_{\text {eff }}$ after the first measured profile are not sensitive to the assumed evolution of the temperature profile before the first measured profile. This is due to the high resistivity of the plasma which prevents the formation of large 
skin currents.

The loop voltage was measured across the ceramic break in the vacuum vessel. Due to noise from the vertical field control system, the loop voltage has been filtered. An inductive correction to the loop voltage $\mu_{0}$ ln $(b / a)$. $\dot{I}_{p}$ ' where $b$ is the vacuum vessel minor radius, was made to obtain the voltage on the surface of the plasma from the measured loop voltage and plasma current.

\section{EXPERIMENT}

In the course of this study, four different conditions were analyzed in detail. These represent a cross section of conditions which have been attained in PLT. Table 1 presents the principal operating differences which will be discussed in more detail later. For each condition figures are presented showing the electron temperature profile, $T_{e}(r, t)$; surface voltage, $v_{s}$ i plasma current, $I_{p} ;$ electron density, $n_{e}$; total power input, $I_{p} \cdot V_{s} ;$ and the calculated quantities $z_{\text {eff }}$; electron energy confinement time, $\tau_{\mathrm{Ee}}$; and ohmic input power, $P_{\mathrm{OH}}$. Neglecting the rate of change of electron energy (which is less than 108 of the ohmic input power) the electron energy replacement time is given by

$$
\tau_{\mathrm{Ee}}=\mathrm{E}_{\mathrm{e}} / \mathrm{P}_{\mathrm{OH}}
$$

where

$$
E_{e}=\int \frac{3}{2} n_{e}{ }^{k T} e^{d V}
$$


$\mathrm{E}_{\mathrm{e}}$ is calculated from the Thomson scattering profiles. The ohmic input power,

$$
\mathrm{P}_{\mathrm{OH}}=\int \mathrm{nj}^{2} \mathrm{dV} \text {, }
$$

is calculated from the computed current density, $j$, and resistivity, $n$, using the results of the one dimensional magnetic field calculation.

The ohmic input power can also be expressed as the difference between the total power into the discharge and the rate of change of stored magnetic energy, $\mathrm{U}_{\mathrm{m}}$;

$$
P_{\mathrm{OH}}=I_{\mathrm{p}} \cdot \mathrm{V}_{\mathrm{s}}-\frac{\mathrm{d}}{\mathrm{dt}} \mathrm{J}_{\mathrm{m}} \text {. }
$$

The one dimensional code predicts the variation of $\mathrm{u}_{\mathrm{m}}=\int \frac{\mathrm{B}_{\theta}^{2}}{2 \mu_{0}} \mathrm{dv}$. The uncertainty in the calculation of the ohmic input power ${ }^{\circ}$ and thus the electron energy confinement time depends upon how well the variation of the stored magnetıc energy is known. As will be shown below, the evolution of the current profile and hence the magnetic field energy is not well known. Two extreme assumptions can be used to obtain upper and lower limits on the ohmic input porer. If the magnetic field did not penetrate at all, then $P_{O H} \sim I_{p} \cdot v_{s}$ and could be as much as a factor of - 2 greater than the calculated ohmic input power. The other extreme is to assume that $j(r, t)$ is proportional to $\sigma(r, t)$ at all times, corresponding to a totally relaxed current profile. In this case, $\mathrm{dU}_{\mathrm{m} / \mathrm{dt}}$ is increased. For example, in the October 24,1978 discharge, the assumption results in the calculation of $1 / 2$ as much of the ohmic input power as the standard magnetic field diffusion model though the difference is significantly 
less in the october 16, 1978 discharge. Thus, the uncertainty in the ohmic input power and hence the electron energy confinement time could be as much as a factor of -2 for these extreme assumptions.

The first experiment (September 29-30, 1976) was conducted with He as the working gas and with tungsten limiters. This experiment relied upon high power pulsed discharge cleaning to condition the vacuum vessel walls. Thj.s technique was not expecially effective in reducing the concentration of oxygen. Thus, the spectroscopically measured $z_{\text {eff }}$ at 20-30 $\mathrm{msec}$ was increased from 2 to $\sim 2.8$ by oxygen and carbon impurities [3]. The average temperature profiles are shown in Fig. 1. They are distinctly hollow but become peaked by $130 \mathrm{msec}$. These temperature measurements had a larger uncertainty than more recent measurements, expecially near the plasma periphery $(x>30 \mathrm{~cm})$. The plasma current, surface voltage and line average microwave density are shown in Fig. 2, and the results of the one dimensional magnetic field diffusion code are shown in Fig. 3. The computed $z_{\text {eff }}$ is within a factor of -2 of the spectroscopic $z_{\text {eff }}$. Considering the large uncertainty in the computed $z_{\text {eff }}$ ( $>50 \%$ ) this is in reasonable agreement with neoclassical current penetration. During the startup phase, this discharge was relatively cold, partially due to the power loss by oxygen and carbon line radiation which accounted for more than $50 z$ of the ohmic input power. Thus the short electron energy confinement time can be attributed in part to low $\mathrm{Z}$ 
impurity radiation. In this discharge due to the low electron temperature and relatively high ${ }_{\text {eff }}$, the neoclassical resistivity was higher than in the other discharges which were studied. Thus, the presence of an enharced current penetration mechanism may have been masked due to the greater plasma resistivity. This discharge, while it does not demonstrate unambiguous enhanced current penetration, does demonstrate why very low impurity concentrations are essential to a study of this kind.

A second set of He discharges with tungsten limiter was run on May 13, 1977. Prior to this experiment extensive low power discharge cleaning was used to condition the vacuun vessel walls. In these discharges, the oxygen and carbon impurity content was less, and $z_{\text {eff }}$ was $\sim 2.1$ at 20-30 msec. The gas influx and the initial fizling pressure were adjusted to minimize tungsten radiation from the core and to contract the current channel during the startup phase. In the very early stages of this discharge, He line radiation and ionization account for nearly all of the ohmic input power, thus playing an important role in the energy balance and formation of the discharge. In this case, the temperature profiles became peaked relatively early, as shown in Fig. 4, and remained peaked throughout the discharge. In the quasi-steady state, tungsten radiation from the core was negligible and the electron energy replacement time was high ( $\geq 40-50 \mathrm{msec})[10]$. During the startup phase, the computed $z_{\text {eff }}$ was considerably greater than the spectroscopic value as shown by a comparison of Table 1 and Fig. 6. 
The following two cases had deuterium as the working gas and stainless steel limiters. In both cases, titanium gettering was used in addition to low power discharge cleaning to condition the vacuum vessel walls. The difference between the two cases was the gas influx during the startup phase. In the first discharge, october 16, 1978, no special effort was made to contract the current profile by adjusting the gas influx. In this case, during the startup phase, the temperature profiles were very hollow (see Fig. 7) and became peaked at $-280 \mathrm{msec}$ into the discharge. The spectroscopic $z_{\text {aff }}$ was $<2$ and computed $Z_{\text {eff }}$ as shown in Fig. 9 was considerably larger.

In the last experiment, October 24,1978 , the temperature and current profiles were deliberately contracted by controlling the influx of gas through a gas feedback system [11]. In this case, early in the discharge the temperature profiles were very peaked on axis as shown in Fig. 10. No spectroscopic measurements were available for this case, but since $z_{\text {eff }}$ in the quasisteady state was the same as in the preceeding discharge $(\sim 1)$, the spectroscopic $z_{\text {eff }}$ should also have been $<2$, which is much less than the computed $z_{\text {eff }}$ (see Fig. 12). Though $\tau_{E e}$ is again short during the startup phase, in the quasi-steady state $\tau_{E e} \approx 50 \mathrm{msec}$.

\section{DISCUSSION}

4.1 Current Fenetration

The analysis of the startup phase of the PLT discharge indicates that a one dimensional magnetic field diffusion code assuming neoclassical registivity was not adequate to describe 
the current penetration phase in a discharge with a relatively low concentration of impurities. In this case, the value of the neoclassical resistivity must be substantially enhanced (in some discharges by about an order of magnitude) to obtain agreement with the experiment. (Since neoclassical resistivity is not linear in $Z_{\text {eff }}$ an enhancement in $z_{\text {eff }}$ of a factor of 15-30 corresponds to only a factor of y-18 enhancement in the resistivity.) These results are in agreement with the observations made in ST [2]. Unlike the ST experiment which indicated that the enhancement in the resistivity was predominantly in the outer region of the discharge, no conclusion can be drawn from the PLT experiments regarding the spatial variation of the enhancement during the current penetration phase.

The presence of the large enhancement of $z_{\text {eff }}$ prevents the formation of a large skin current; however, the current distribution predicted by the one dimensional code is not completely relaxed. This is illustrated in Fig. 13 where the current profile from the one dimensional code calculation is compared with the assumption $j \alpha$ o which corresponds to a completely relaxed profile.

The mechanism responsible for the enhanced current penetration has not been identified on PLT. On LT-3, Hutchinson and Morturi [12] using magnetic probes observed the appearance of an $m=4$ tearing mode and rapid relaxation of the curxent distribution in $\sim 200 \mu \mathrm{sec}$. Also S. V. Mirnov and I. B. Semenov attributed the relaxation of the current channel in T4 to accompanying 
magnetic fluctuations [13]. Similarly Granetz et al. on Aicator have studied disruptive MHD activity during the scartup phase [14]. Sudden changes (including sudden decreases) in the $\ell_{i} / 2+\beta_{\theta}$ measurements in both PIT and PDX indicated that the current channel can undergo rapid changes. Thus our assumed gradual enhanced current penetration may be an approximation to a multitude of small sudden current relaxatinns.

In addition to these experimental studies, several theoretical studies of the MHD stability of the current profiles to tearing modes have been conducted. Whor the radius is a couble valued Iunction of $g$, as in the case of hollow current profile, tearing modes are unstable 115]. White et al. [16; have shown that under these conditions the effect of tearing modes is to flatten the q profile. However, more recert calculations of Carreras et al. [17] indicate that instead of flattening the q profile the development of two sets of saturated islands can also occur.

In order to investigate the effect of tearing modes on relaxing the current profile, the current mixing model of Dnestrovskii et al. [18] was employed. In this model the $q$ profile is flattenea when the helical flux at the inner rational surface is equal to its boundary value. This criterion is admittedly ad hoc, but it does give the maximum mixing region. This model was used $10-30 \mathrm{msec}$ into the discharge. During these times, the temperature is fairly well known and the neoclassical predictions are in poor agreement with the experiment. Once again the poloidal field on the boundary was determined by the experimental value. However, in these calculations, 
for the October 16, 1978 and October 24, 1978 data, $Z_{\text {eff }}$ was assumed to be two in the calculation of the neoclassical resistivity, corresponding to an upper limit on the resistivity. In this case, the computed surface voltage was compared with the experimental value. Using this approach without the current mixing model, the computed surface voltage is less, as expected, than the experiment value, The current mixing model of Ref.

18 did not significantly change this computed value of the surface voltage, even though a pattern of reconnection events similar to those show in Ref. 18 were observed during the simulation. However, the applicability of this model to our experiment is uncertain, because of the many rational surfaces present. The radius was sometimes a triple valued or even a quadrupie valued function of the safety factor according to these calculations. Since the model of Ref. 18 was postulated only for cases where the radius is a double valued function of the safety factor we had to limit our reconnection to the outer two surfaces.

A generalization of the mixing model of Ref. 18 to cases where many rational surfaces are present is possible, but first 2-D calculations similar to the work of Refs. 16 and 17 should be done to determine the proper criterion for when reconnection takes place. An alternate approach, which is in progress, is to use the discharge data as input to a 3-D nonlinear code and follow the evolution of a mixture of helicities. Such calculations would conceivably clarify the role of tearing modes in the current penetration process. 
In addition to the MHD activity, microinstabilities can theoretically also enhance the current penetration process (e.g. Ref. 5), but unfortunately fluctuation measurements were not performed during this experiment.

\subsection{Electron Energy Confinement}

The electron energy confinement time in all of the discharges studied is much shorter in the startup phase than in the quasi-steady state. This is in agreement with observation on the ST tokamak [19]. In order to compare the confinement time in the startup phase with the quasi-steady-state, it is necessary to know the parametric dependence of the confinement time, since the plasma parameters are different during these two phases of the discharge. If empirical scaling laws derived from quasi.*steady-state conditions [20-24] are extrapolated to the startup phase, they predict an energy confinement time considerably greater than that actually observed. Thus, the empirical scaling laws cannot be used during the startup phase. This may be due to the diffexences in the radiative energy loss mechanism between the early and late times in the aischarge.

Despite the short electron energy confinement time and the resulting low electron temperature, the neoclassical conductivity is too large to enable the current profile to penetrate. Thus, merely increasing the electron heat conductivity in one dimensional computer simulations of the startup phase will not fit our data $[1,25\}$. 
McBride et al. [5] suggested that neoclassical ion heat conduction may be important in the overall power balance in the startup phase. For PLT conditions during the startup phase, the power flow due to neoclassical ion heat conduction is much smaller than the ohmic input power. For neoclassical ion heat conduction to be a dominant loss mechanism, the electron dessities would have to be considerably larger. In PLT, this parameter regime is inaccessible because of plasma disruptions.

\section{CONCLUSIONS}

The conclusions of this study may be summarized as follows:

1) Current penetration during the startup phase cannot be modeled by simple magnetic field diffusion due to neoclassical resistivity. The discrepancies appear to increase when the neoclassical resistivity is less. clearly this is important in future one dimensional modeling of the startup phase.

2) The electron energy confinement time is significantly decreased compared with the value during the quasi-steady state, and also iess than the value obtained by extrapolating on the basis of empirical scaling laws.

3) Even with enhanced current penetration, hollow temperature and current profiles can occur in discharges with low concentrations of low $z$ impurities and low rates of gas influx. Typically, such profiles do not persist throughout the discharge but become peaked in the quasi-steady state. 


\section{ACKNOWLEDGMENTS}

We gratefully acknowledge the numerous helpful discussions with $K$. Bol as well as the support and encouragement of $W$. Stodiek and J. A. Schmidt.

This work is supported by the United States Department of Energy, Contract No. EY-76-C-02-3073. 
REFERENCES

[1] DÜCHS, D.F., EURTH, H.P., RUTHERFORD, P.H., Nucl. Fusion $\underline{12}$ (1972) 341 .

[2] HOSEA, J.C., Symposium on Plasma Heating in Toroidal Devices, Varenna, Italy, Editrice Composition (1974) 189.

[3] HINNOV, E., SUCKEWER, S., BOL, K., HAWRYLUK, R.J., HOSEA, J., and MESERVEY, E., Plasma Physics 20 (1978) 723.

[4] BOL, K. et al., in Plasma Physics and Controllec Nuclear Fusion Research (Proc. 7th Int. Conf. Innsbruck, 1978) 7. IAEA, Vienna (1979), 11.

[5] MCBRIDE, J.B., KLEIN, H.H., BYRNE, K.N., KRALL,N.A., Nucl. Fusion 15 (1975) 393.

[5] DÜCHS, D.F., POST, D.E., RUTHERFORD, P.H., Nucl. Fusion 17 (1977) 565 .

[7] ROSS, DAVID W., CARDWELL, GEORGE L., Physics of Fluiōs, 16 (1973) 1551 .

[8] HIRSHMAN, S.P., HAWRYLUK, R.J., BIRGE,B., Nucl. Fusion 17 (1977) 61i.

[9] BRETZ, N., DIMOCK, D., FOOTE, V., JOHNSON, D., LONG, D., TOLNAS, E., Appl. Optics 17, (1978) 192.

[10] ARUNASALAM, V., et al., Proc., Eighth European Conference on Controlled Fusion and Plasma Physics (Prague, 1977) Vol. II, p. 17-28, also Princeton Plasma Physics Laboratory PPPL$1436(1978)$. 
[11] HAWRYLUK, R.J., BOL, K., BRETZ, N., DIMOCK, D., EAMES, D., HINNOV, E., HOSEA, J.C., JOBES, F.C., JOHNSON, D., MESERVEY, E., SAUTHOFF, N., SCHMIDT, G.L., SUCKEWER, S., ULRICKSON, M., and VON GOELER, S., to be published in Nuclear Fusion (1979).

[12) HUTCHINSON, H., and MORTON, A.H., Nucl. Fusion 16 (1976) 474.

[13] MIRNOV, S.V., and SEMENOV, I.B., Fizika Plasmi, 4 (1978) 50 .

[14] GRANETZ, ROBERT S., HUTCHINSON, IAN H., OVERSKEI, DAVID O., Bull. Am. Phys. Soc. 9510 (1978) 902.

[15] FURTH, H.P., RUTHERFORD, P.H., and SELBERG, H., Nucl. Fusion 16 (1973) 1054 .

[16] WHITE, R.B., MONTICELLO, D.A., ROSENBLUTH, M.N., and WADDELL,B.V., Conf. Plasma Physics and Controlled Nuclear Fusion Research Paper IAEA-CN-35/B2-1 (1976).

[17] CARRERAS, B., HICKS, H.R., and WADDELL, B.V., Nuclear Fusion 19, (1979) 583 .

[18] DNESTROVSKII, YU. N., KOSTOMAROV, D.P., LYSENKO, S.E., PEREVERzEV, G.V., and TARASYAN, K.N., Conf. Plasma Physics and Controlled Nuclear Fusion Research Paper IAEA-CN-37-F-1-3 (1978).

[19] DIMOCK, D.L., EUBANK,H.P., HINNOV, E., JOHNSON, I.C., and MESERVEY, E., Nucl. Fusion, 13 (1973) 271.

[20] MIRNOv, s.v., Conf. Plasma Physics and Controlled Nuclear Fusion Research Paper, IAEA-CN-37-F-1-2 (1978). 
[21] DAUGHNEY, C.C., Princeton Plasma Physics Laboratory Report PPPL-1442 (1978).

(22) JASSBY, D.L., COHN, D.R., PARKER, R.R., Nuclear Fusion 16. (1976) 1045 .

[23] PFEIFFER, W.W., WALTZ, R.E., Nuclear Fusion 19, (1979) 51.

[24] COPPI, B., and MAzzUCATU, E., Phys. Lett. 71A, (1979) 337.

[25] KLEIN, H.H., COTSOFTIS, M., KRALL, N.A., and MCBRIDE, J.B., Phys. Rev. Lett. 42, (1979) 1144. 
TABLE 1

\begin{tabular}{|c|c|c|c|c|}
\hline Date & Limitex & Gas & $\begin{array}{l}\text { Wall Conditioning } \\
\text { Method }\end{array}$ & $\begin{array}{c}\text { Spectroscope } \\
z_{\text {eff }}\end{array}$ \\
\hline sept. $29-30,1976$ & $\mathrm{~W}$ & He & $\begin{array}{l}\text { High Power Pulsed } \\
\text { Discharge Cleaning }\end{array}$ & 2.8 \\
\hline May 13,1977 & $\mathbf{W}$ & He & $\begin{array}{l}\text { Low Power Pulsed } \\
\text { Discharge Cleaning }\end{array}$ & 2.1 \\
\hline $\begin{array}{l}\text { Oct. } 16,1978 \\
\text { Oct. } 24,1978\end{array}$ & $\begin{array}{l}\text { Stainless Steel } \\
\text { Stainless Steel }\end{array}$ & $\mathrm{D}$ & $\left\{\begin{array}{l}\text { Low Power Pulsed } \\
\text { Discharge Cleaning } \\
\text { and } T_{i} \text { Gettering }\end{array}\right.$ & $\begin{array}{l}<2 \\
<2\end{array}$ \\
\hline
\end{tabular}




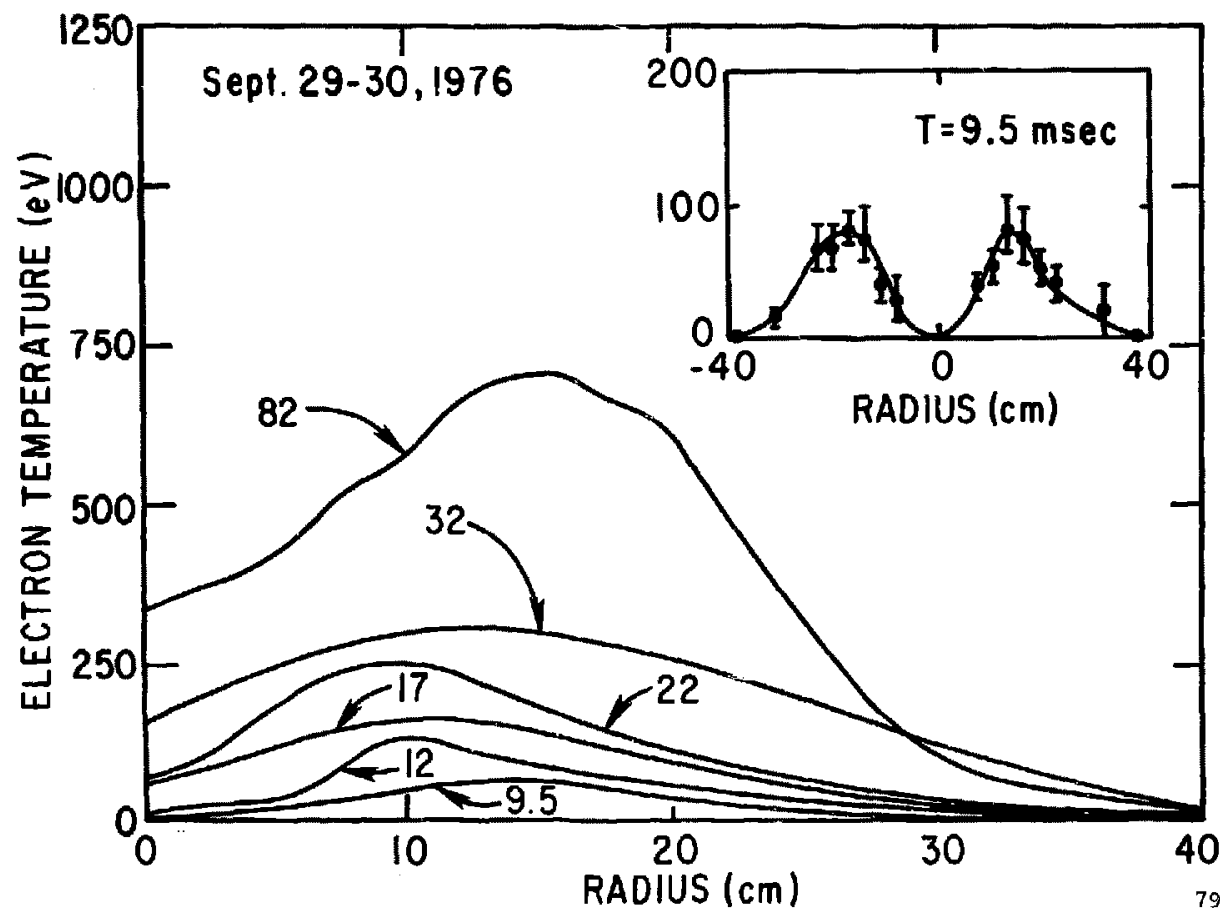

Fig. 1. Thomson scattering temperature profiles for heliun discharges of september 29-30, 1976. The numbers indicate the time after the initiation of the discharge. The insert shows the actual measurements at $9.5 \mathrm{msec}$ into the discharge. 


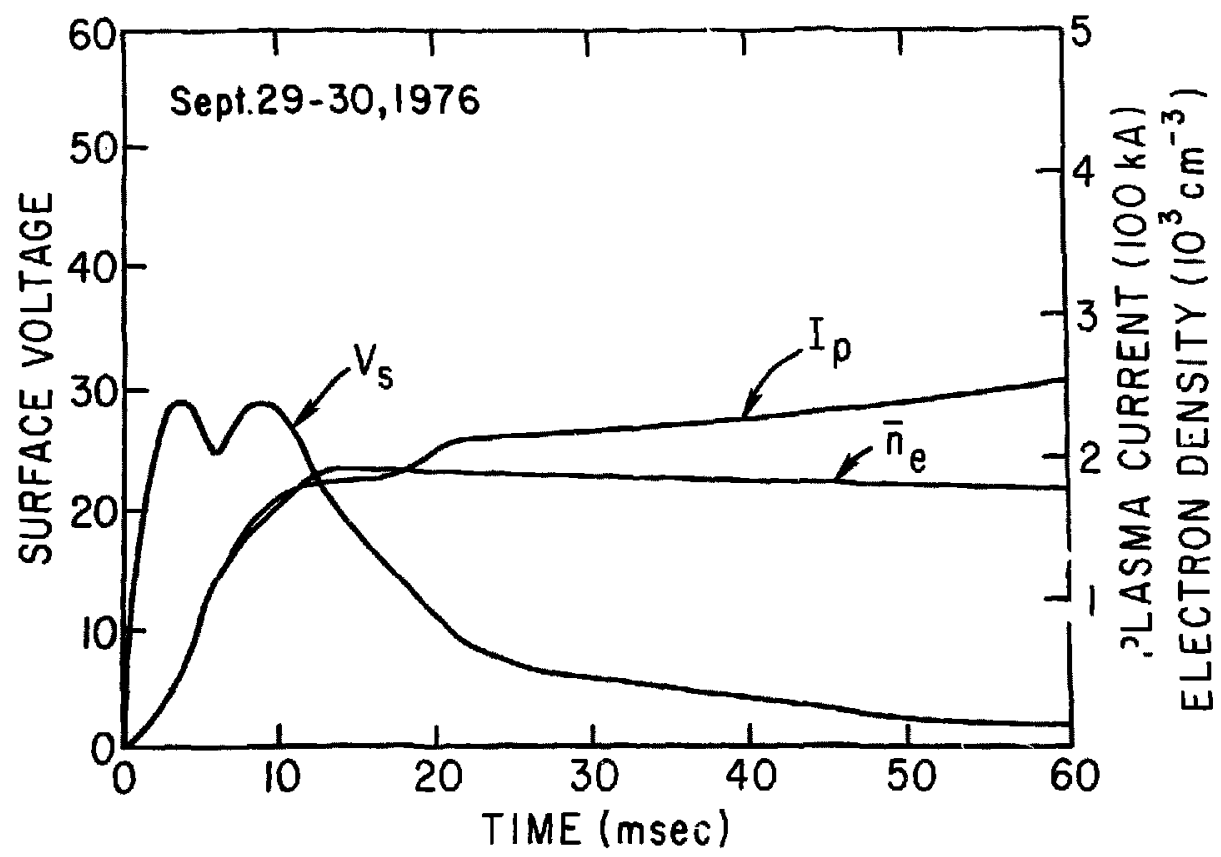

796315

Fig. 2. For September 29-30, 1976, measurements of plasma current, surface voltage and line average density. 
$-22-$
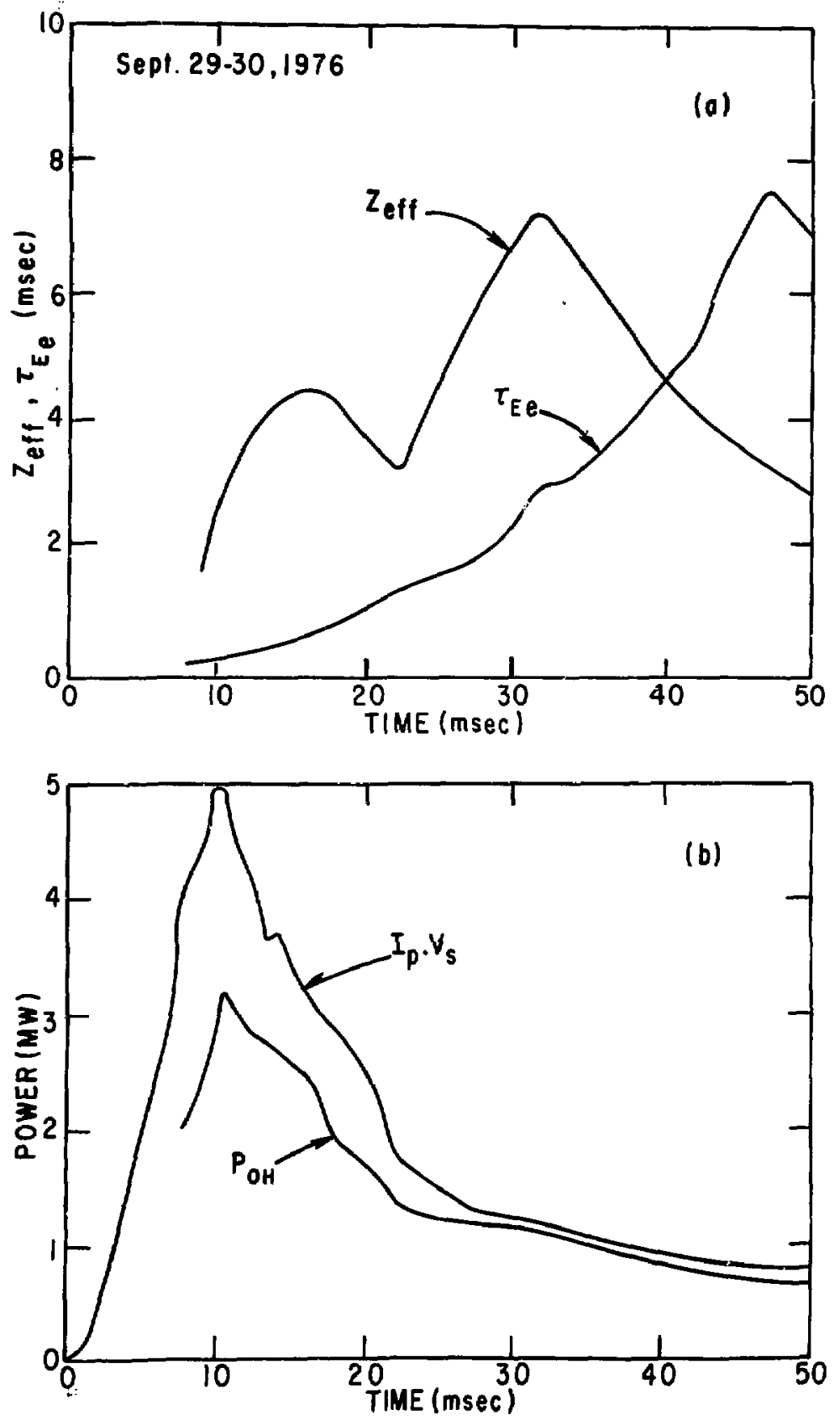

Fig. 3. For September 29-30, 1976, the calculated $z_{\text {eff, }} \tau_{\mathrm{Ee}}$, and ohmic heating power and total power into the discharge, $I_{p} \cdot V_{s}$. 


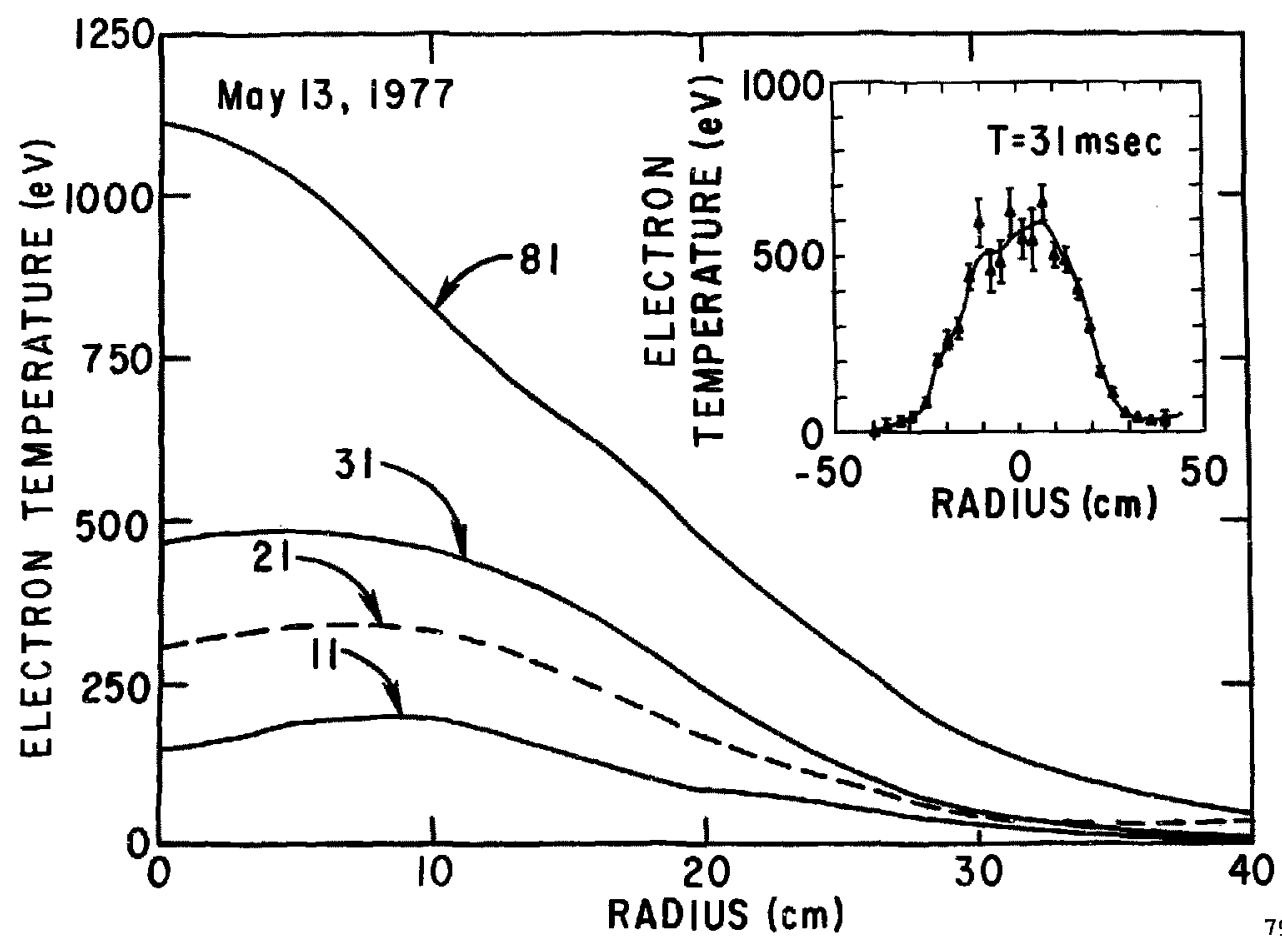

796271

Fig. 4. Thomson scattering temperature profiles for helium discharges of May $13,1977$. The numbers indicate the time after the initiation of the discharge. The insert shows the actual measurements at 31 msec into the discharge. 


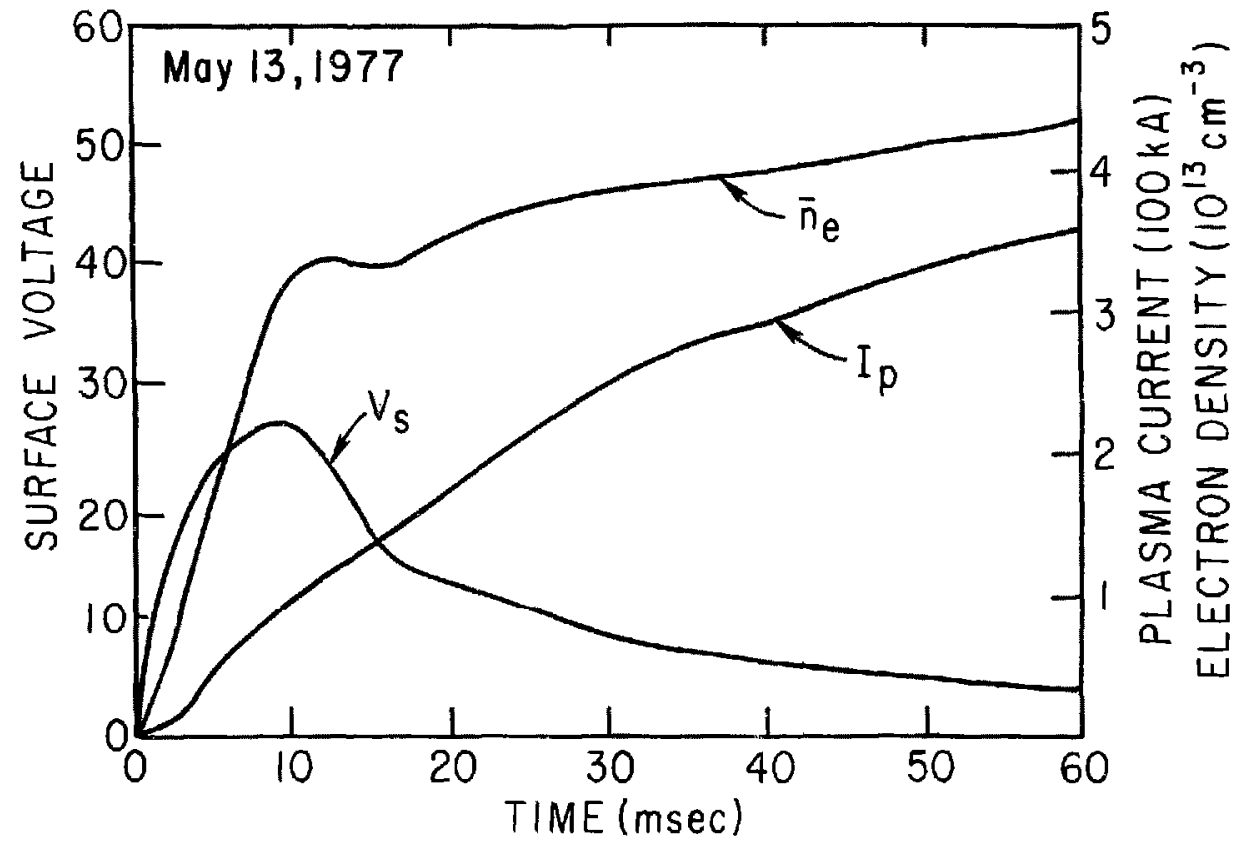

796216

Fig. 5. For May 13, 1977, measurements of plasma current, surface voltage and line average density. 

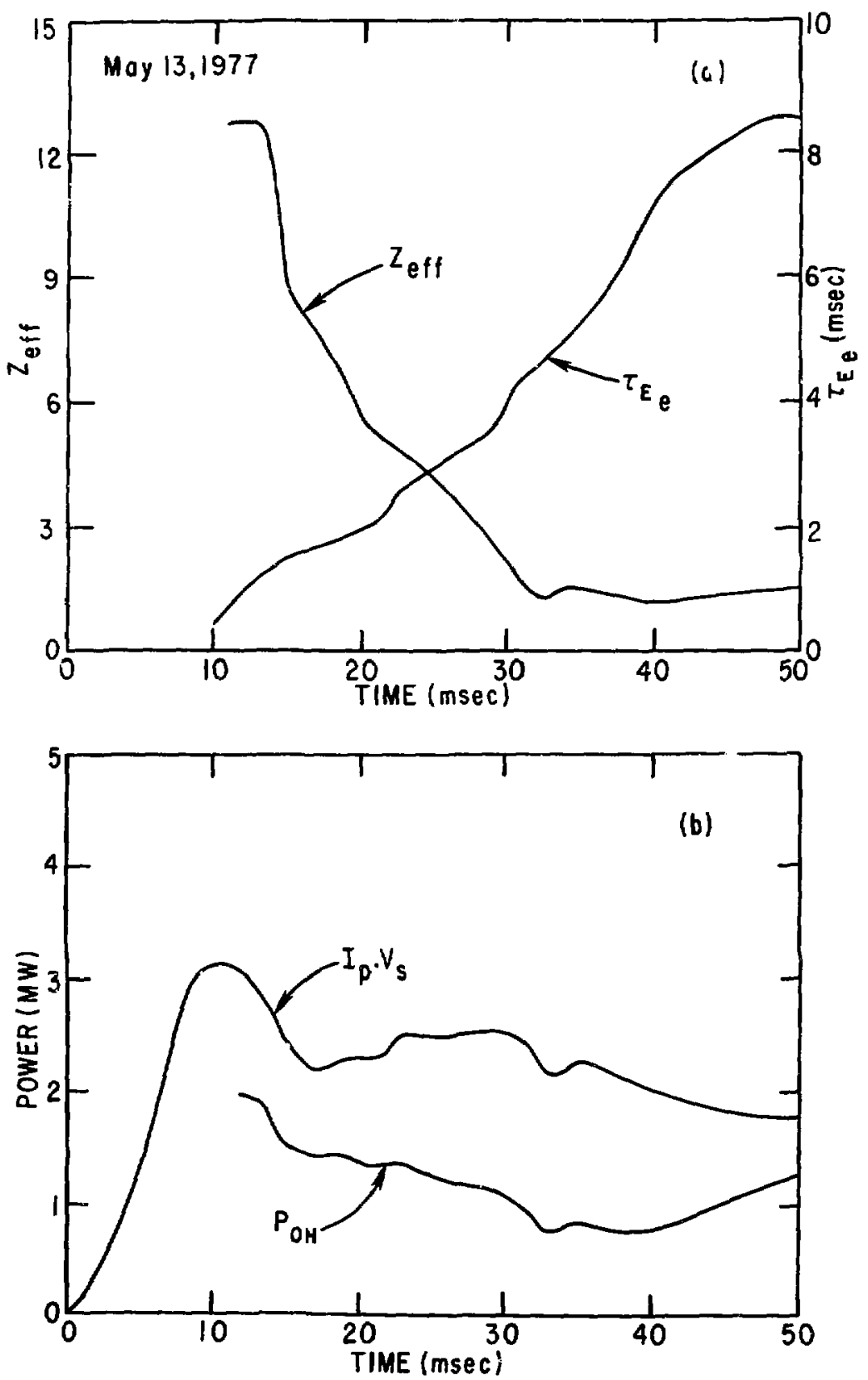

796268

Fig. 6. For May 13, 1977, the calculated $3_{\text {eff, }}$ $\tau_{E e}$, ohmic heating power and total power into the discharge, $I_{p} \cdot V_{s}$. 


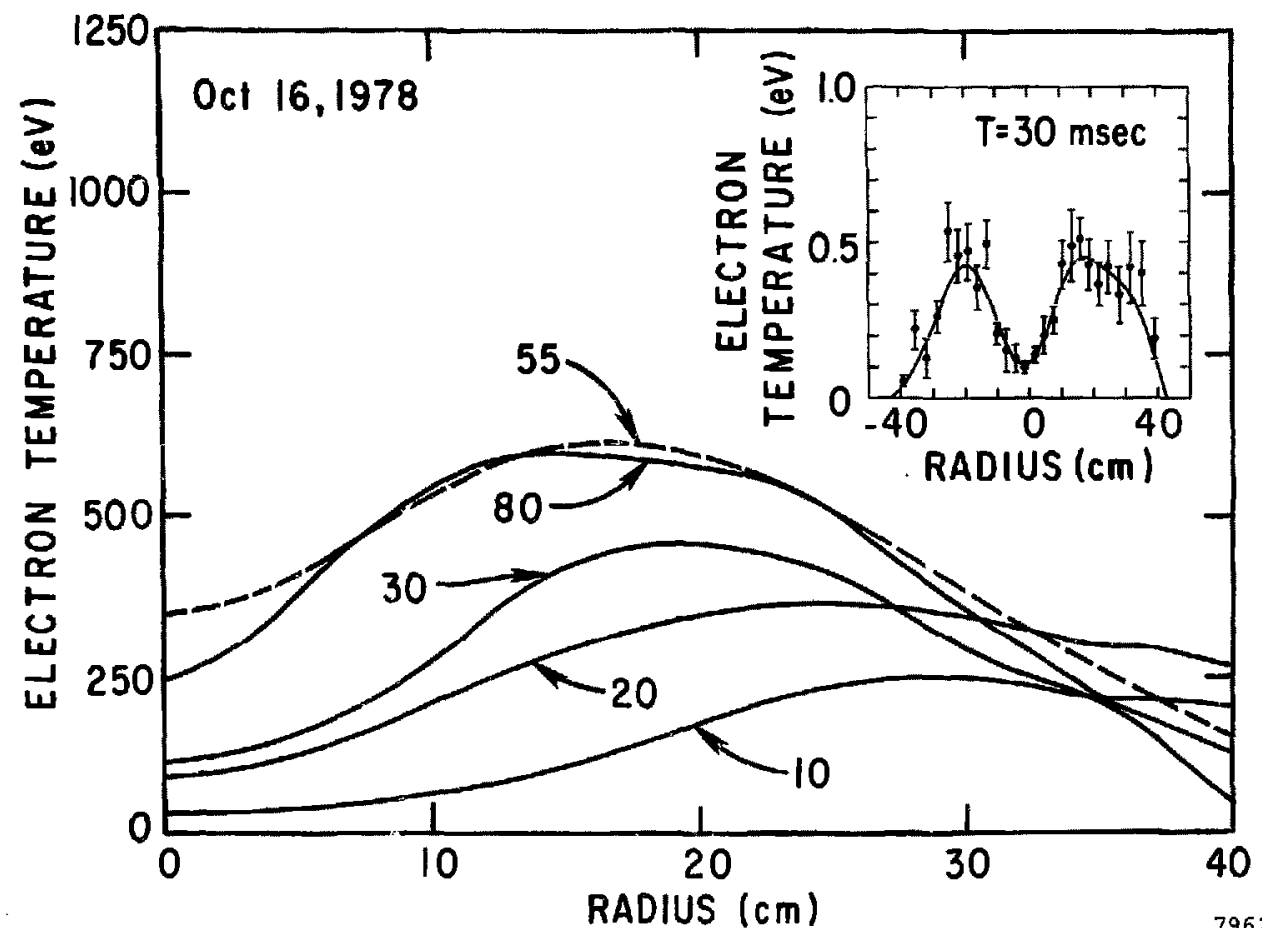

Fig. 7. Thomson scattering temperature profiles for deuterium discharges of october 16, 1978. The numbers indicate the time after the initiation of the discharge. The insert shows the actual measurements at 30 msec into the discharge. 


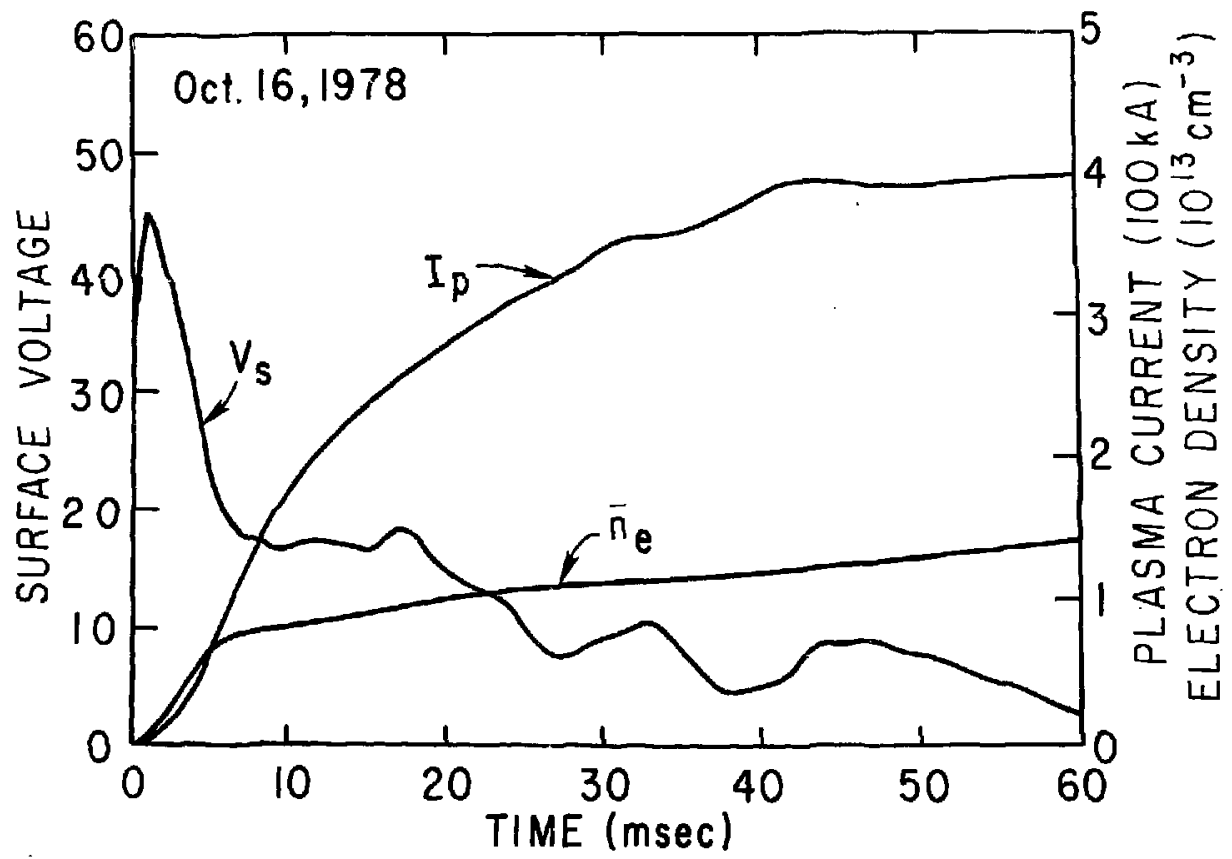

Fig. 8. For October 16, 1978, measurements of plasma current, surface voltage and line average density. 

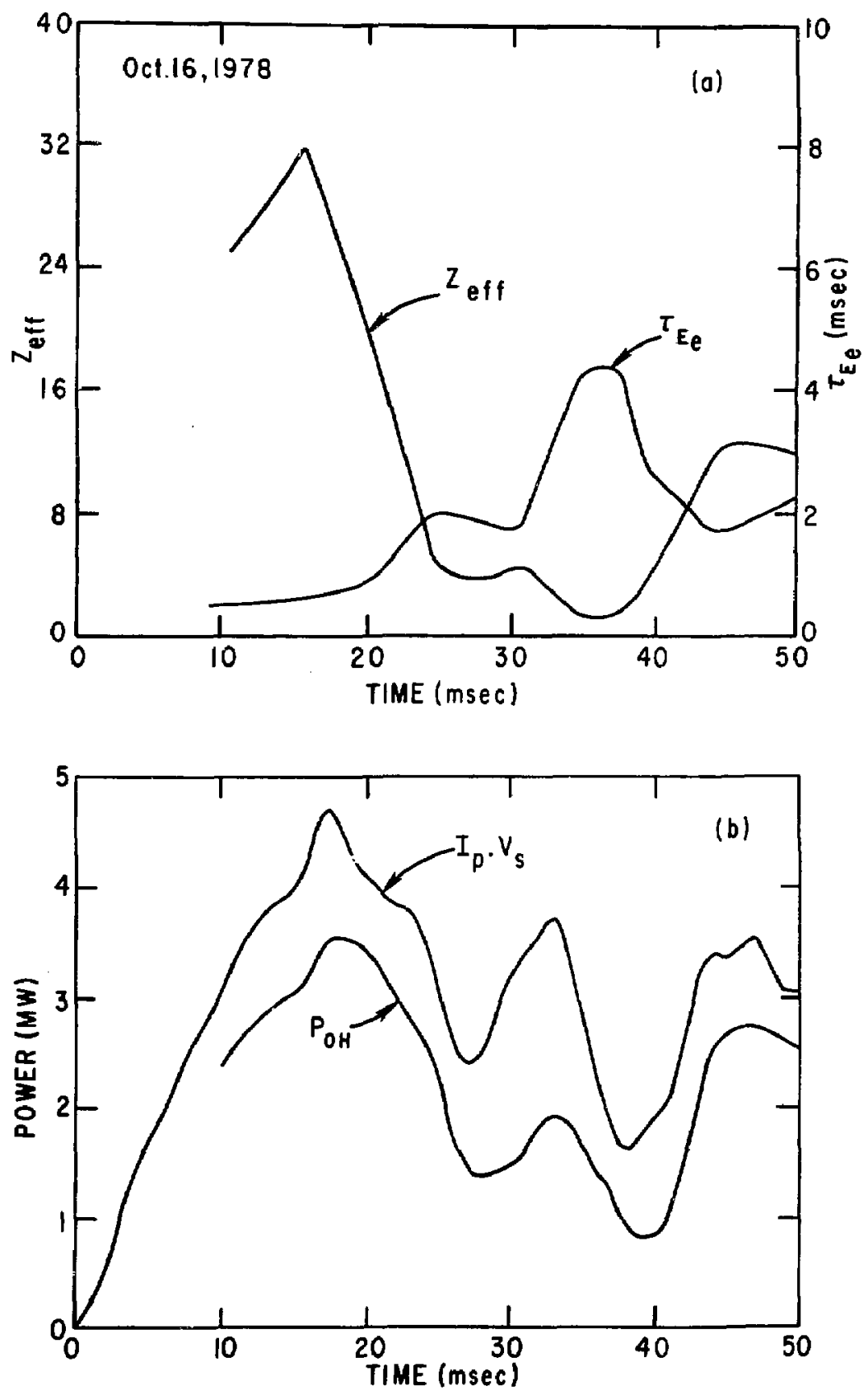

796265

Fig. 9. For October 16, 1978, the calculated $Z_{\text {eff, }}{ }_{\mathrm{Ee}}$ ' ohmic heating power and total power into the discharge, $I_{p} \cdot V_{s}$. 


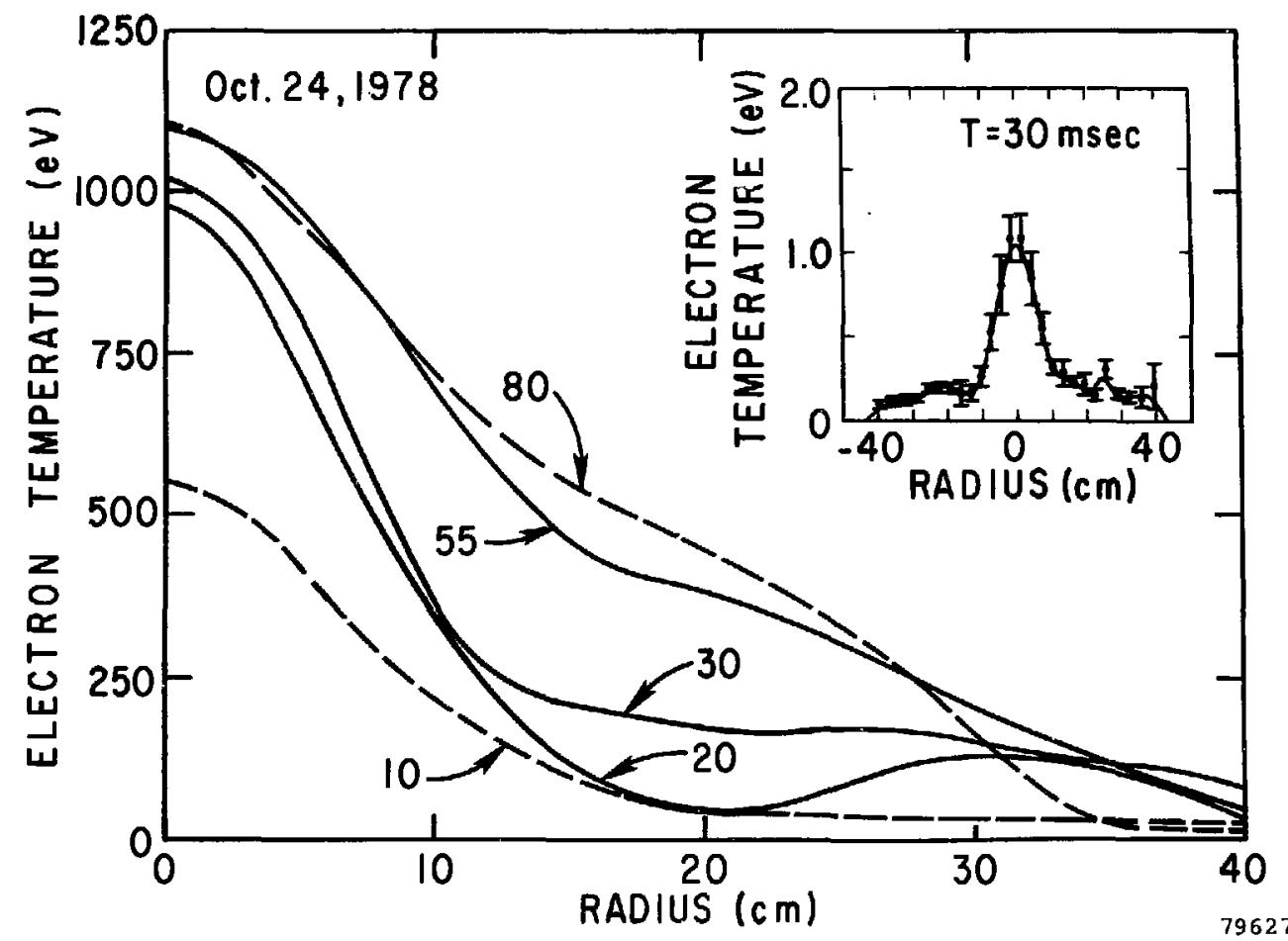

796270

Fig. 10. Thomson scattering temperature profile for deuteriun discharges of october 24, 1978. The numbers indicate the time after the initiation of the discharge. The insert shows the actual measurement at $30 \mathrm{msec}$ into the discharge. 


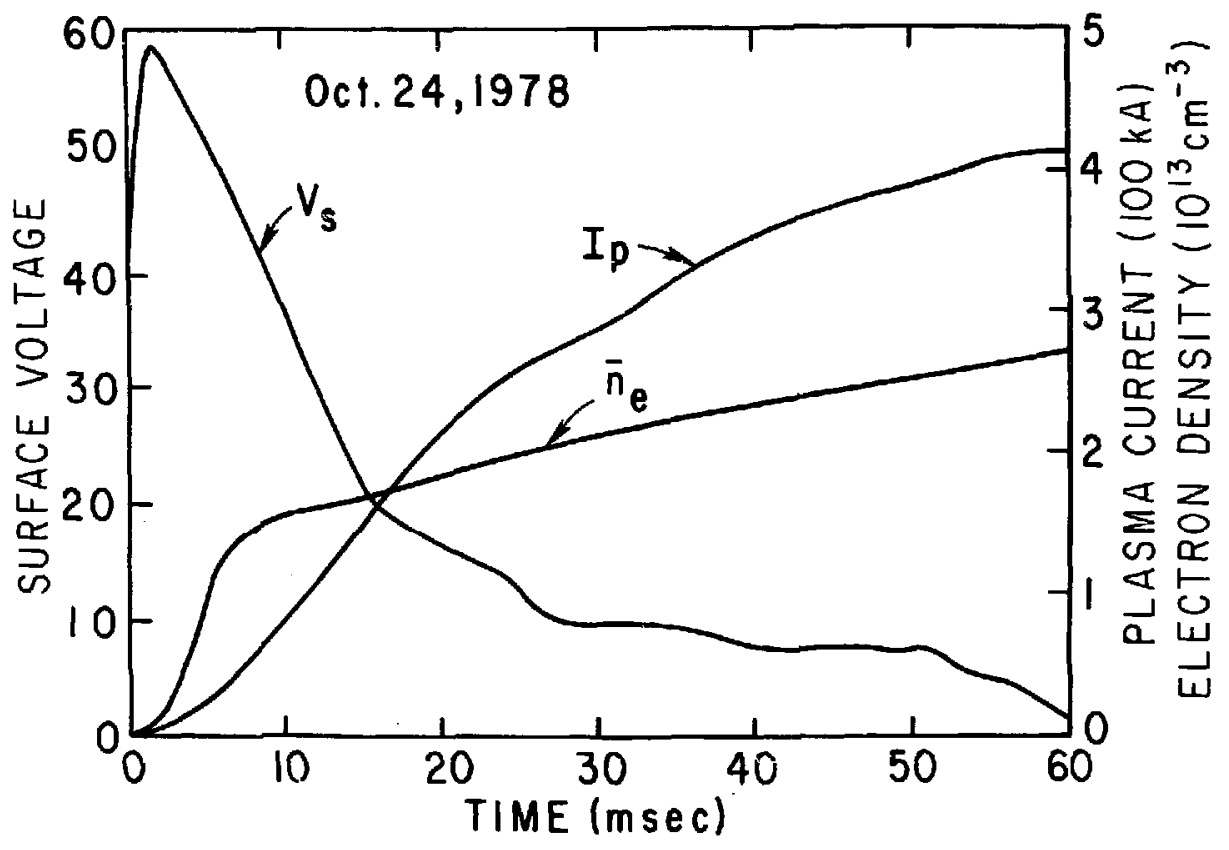

796218

Fig. 11. For october 24, 1978, measurements of plasma current, surface voltage and line average density. 

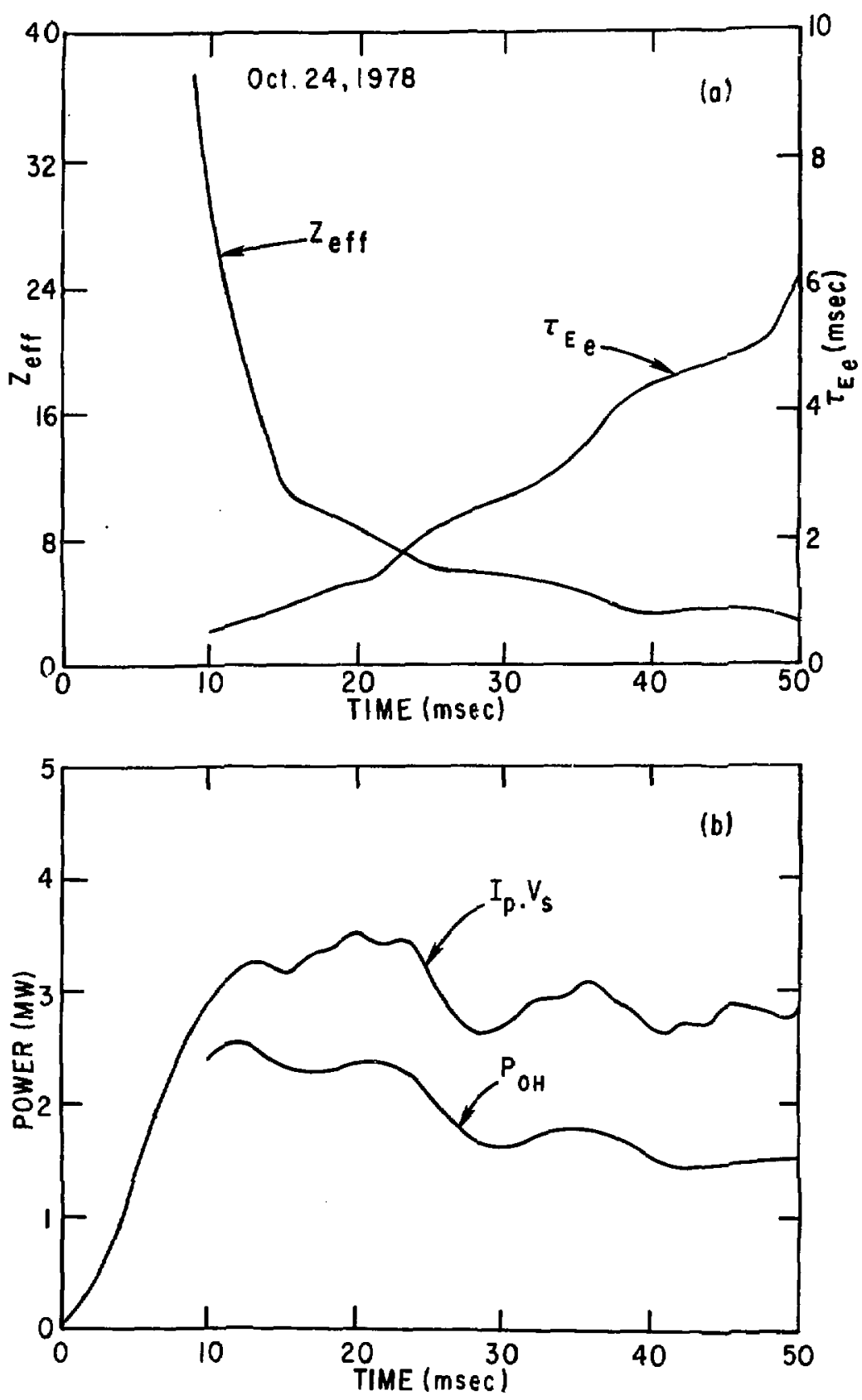

796267

Fig. 12. For October 24, 1978, the calculated Zeff, $\tau_{E e}$, ohmic heating power and total power into the discharge, $I_{p} \cdot V_{s}$. 


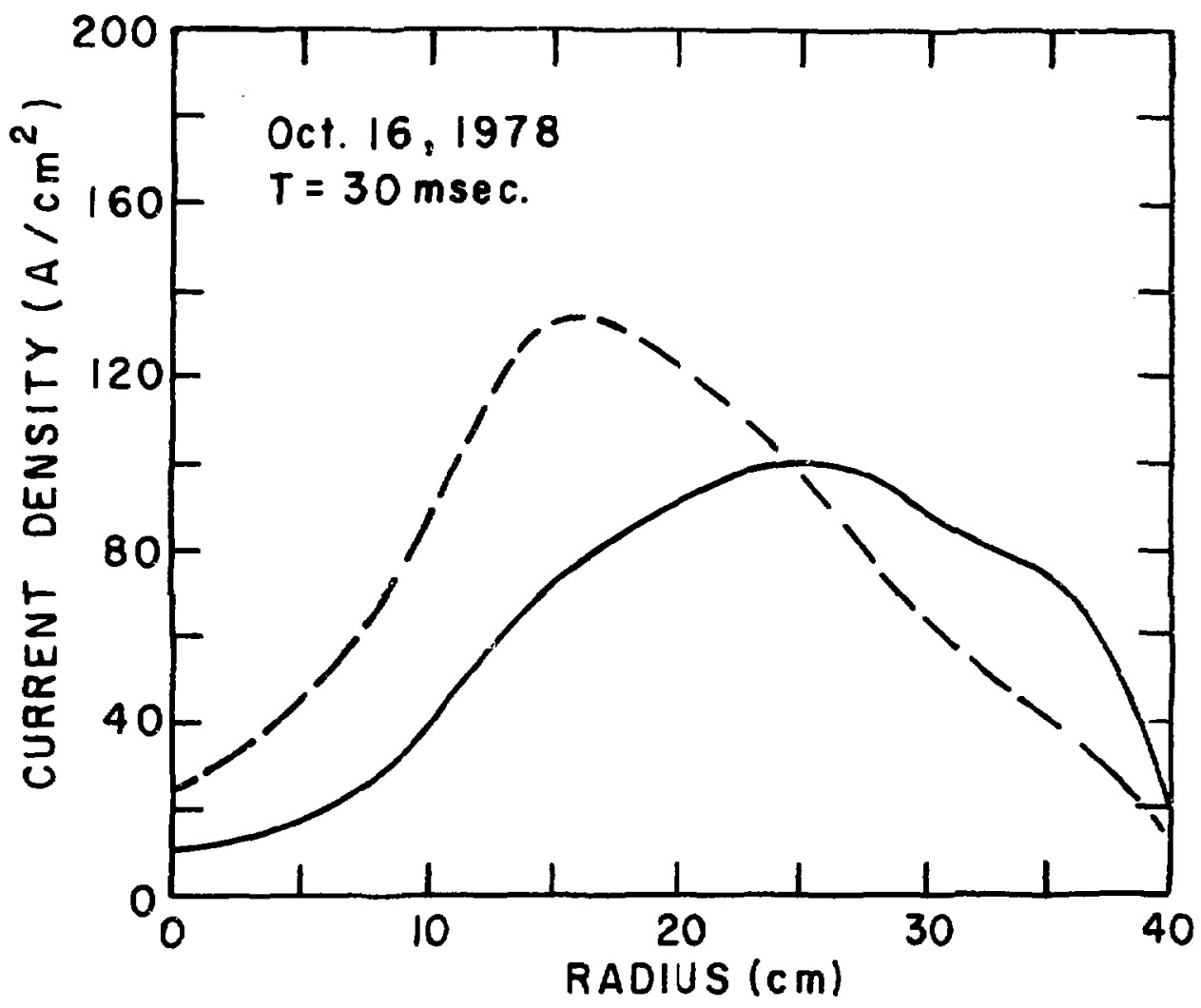

Fig. 13. The calculated current density profile 796217 line) using one dimensional magnetic field diffusion code is compared with the current profile assuming that $j \alpha \sigma$ (dotted line). 